\title{
Publisher Correction: Strongly-coupled quantum critical point in an all-in-all-out antiferromagnet
}

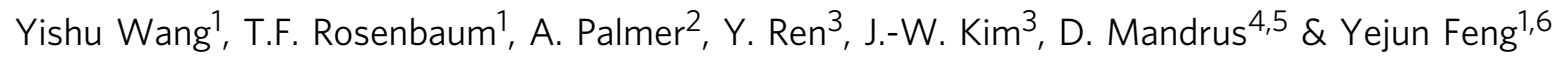 \\ Correction to: Nature Communications https://doi.org/10.1038/s41467-018-05435-7; published online 27 July 2018
}

The original PDF version of the Article contained an error in the last sentence of the author affiliation information, which incorrectly read 'Correspondence and requests for materials should be addressed to T.\$.R. (e-mail: tfr@caltech.edu) or to Y.F. (e-mail: yejun@oist. jp)'. The correct version states 'T.F.R.' in place of “T.\$.R.'. This has been corrected in the PDF version of the Article. The HTML version was correct from the time of publication.

Published online: 05 September 2018

(c) Open Access This article is licensed under a Creative Commons Attribution 4.0 International License, which permits use, sharing, adaptation, distribution and r reproduction in any medium or format, as long as you give appropriate credit to the original author(s) and the source, provide a link to the Creative Commons license, and indicate if changes were made. The images or other third party material in this article are included in the article's Creative Commons license, unless indicated otherwise in a credit line to the material. If material is not included in the article's Creative Commons license and your intended use is not permitted by statutory regulation or exceeds the permitted use, you will need to obtain permission directly from the copyright holder. To view a copy of this license, visit http://creativecommons.org/licenses/by/4.0/.

(c) The Author(s) 2018

\footnotetext{
${ }^{1}$ Division of Physics, Mathematics, and Astronomy, California Institute of Technology, Pasadena, CA 91125, USA. ${ }^{2}$ Department of Physics, The James Franck Institute, The University of Chicago, Chicago, IL 60637, USA. ${ }^{3}$ The Advanced Photon Source, Argonne National Laboratory, Argonne, IL 60439, USA.

${ }^{4}$ Department of Materials Science and Engineering, University of Tennessee, Knoxville, TN 37996, USA. ${ }^{5}$ Materials Science and Technology Division, Oak Ridge National Laboratory, Oak Ridge, TN 37831, USA. ${ }^{6}$ Okinawa Institute of Science and Technology Graduate University, Onna, Okinawa $904-0495$, Japan. Correspondence and requests for materials should be addressed to T.F.R. (email: tfr@caltech.edu) or to Y.F. (email: yejun@oist.jp)
} 